\title{
What is the Incoherence Objection to Legal Entrapment?
}

\begin{abstract}
Some legal theorists say that legal entrapment to commit a crime is incoherent. So far, there is no satisfactorily precise statement of this objection in the literature: it is obscure even as to the type of incoherence that is purportedly involved. (Perhaps consequently, substantial assessment of the objection is also absent.) We aim to provide a new statement of the objection that is more precise and more rigorous than its predecessors. We argue that the best form of the objection asserts that, in attempting to entrap, law-enforcement agents lapse into a form of practical incoherence that involves the attempt simultaneously to pursue contrary ends. We then argue that the objection, in this form, encompasses all cases of legal entrapment only if it is supplemented by appeal to the premise that law-enforcement agents have an absolute duty never to create crimes.
\end{abstract}

Keywords: contrariety of ends, entrapment, incoherence, integrity, irrationality, legal entrapment 


\section{Legal Entrapment to Commit a Crime}

Cases of entrapment involve an entrapping party, whom we call the 'agent', and an entrapped party, whom we call the 'target'. Let the terms 'party', 'agent' and 'target' encompass both individuals and groups. The word 'entrap' is a verb of success: if A entraps B then A successfully entraps B. (It thus differs from a phrase like 'to look for': it makes perfect sense to say 'I looked for it unsuccessfully'.)

We draw two distinctions, which cut across each other, concerning acts of entrapment. The first concerns the status of the agent; the second concerns the act that the target performs and that the agent procures.

Legal entrapment occurs when the agent is a law-enforcement officer, acting (lawfully or otherwise) in their official capacity as a law-enforcement officer, or when the agent is acting on behalf of a law-enforcement officer, as their deputy. When, on the other hand, the agent is neither a law-enforcement officer acting in that capacity, nor the deputy of such an officer, acting in their capacity as deputy, we have civil entrapment. ${ }^{2}$

We distinguish between procured acts of criminal and of non-criminal types. An investigative journalist might entrap a politician into performing a morally compromising act that is not a crime, in order that the journalist might expose the politician for having performed the act. When the act is non-criminal but is morally compromising (whether by being immoral, embarrassing or socially frowned upon in some way), we are dealing with 'moral' entrapment (using the word 'moral' in a wide sense). When the act is of a criminal type, we have 'criminal' entrapment.

\footnotetext{
${ }^{1}$ This section summarizes REDACTED.

${ }^{2}$ For details of alternative terminologies for the legal/civil distinction, see (n 1) REF.
} 
Thus, four types of entrapment can be distinguished: legal criminal entrapment (e.g., the police entrap someone into dealing in illegal drugs), civil criminal entrapment (e.g., a journalist entraps someone into dealing in illegal drugs), civil moral entrapment (e.g., a journalist entraps a politician into making an embarrassing boast) and legal moral entrapment (e.g. when lawenforcement agencies, in their capacities as law-enforcement agents, entrap someone into performing a morally compromising act that is not a crime). Our concern in this article is with an objection to legal entrapment to commit a crime. Henceforth, we use 'legal entrapment' as an abbreviation for 'legal criminal entrapment'. When this sort of entrapment occurs, we take it, the following conditions are all met:

(i) a law-enforcement agent (or the agent's deputy), acting in an official capacity as (or as a deputy of) a law-enforcement agent, plans that the target perform an act;

(ii) the act is of a type that is criminal;

(iii) the agent procures the act (using solicitation, persuasion or incitement);

(iv) the agent intends that the act should, in principle, be traceable to the target either by being detectable (by a party other than the target) or via testimony (including the target's confession), that is, by evidence that would link the target to the act;

(v) in procuring the act, the agent intends to be enabled, or intends that a third party be enabled, to prosecute (or threaten to prosecute) the target for having performed the act. ${ }^{3}$

\footnotetext{
${ }^{3}$ We intend condition (v) to include blackmail cases in which the agent intends not that the target will be prosecuted, but that the target will be placed under threat of prosecution. Many writers hold (which we do not) that entrapment necessarily involves deception. These include: Gerald Dworkin, 'The Serpent Beguiled Me and I Did Eat: Entrapment and the Creation of Crime' (1985) 4 Law and Philosophy 17, 30, reprinted in his The Theory and Practice of Autonomy (CUP 1988), Chapter 9; Jerome H. Skolnick, 'Deception by Police' in Frederick A. Elliston and Michael Feldberg (eds), Moral Issues in Police Work (Rowman \& Littlefield 1985) 81; John Kleinig,
} 
Condition (ii) states that the entrapped act is of a type that is criminal. We are not here concerned with whether the target's token act is one for which the target is criminally liable. In our experience, to say that the target's token act is a crime suggests to some readers that the act is one for which the target is criminally liable. We seek to avoid this mistaken impression, and to provide a definition of entrapment that prejudges neither the question of the target's criminal liability nor that of the permissibility of entrapment.

\section{Procurement and the Creation of Crime}

When defining entrapment, some theorists include a counterfactual (or 'but for') condition, according to which the target has been entrapped only if the target would not have committed the crime but for the agent's actions. For reasons we have explained elsewhere, we do not consider it necessary or desirable to include such a counterfactual condition. ${ }^{4}$ Nevertheless, we note that while some theorists that include a counterfactual condition appeal to the token side of the type/token distinction, others appeal to the type side. ${ }^{5}$ On that approach, it is a necessary condition of a target's being entrapped into committing a crime that, but for the entrapment,

The Ethics of Policing (CUP 1996) 153; Seamus Miller and John Blackler, Ethical Issues in Policing (Ashgate 2005) 104; Seamus Miller, John Blackler and Andrew Alexandra, Police Ethics (2nd edn, Waterside Press 2006) 263; Hock Lai Ho, 'State Entrapment' (2011) 31 Legal Studies 71, 74. For full discussion and defence of our conditions, and of our omission of any deception condition, see (n 1) REF.

${ }^{4}$ See (n 1) REF.

${ }^{5}$ The token side of the distinction is adopted by B. Grant Stitt \& Gene G. James in two articles: 'Entrapment and the Entrapment Defense: Dilemmas for a Democratic Society’ (1984) 3 Law and Philosophy 111; 'Entrapment: An Ethical Analysis', in Frederick A. Elliston and Michael Feldberg (eds), Moral Issues in Police Work (Rowman \& Littlefield 1985) 130. It is also adopted by Gerald Dworkin (n 3) 30. For a definition of entrapment that appeals to the type side of the type/token distinction, and which is therefore inconsistent with the conception of the creation of crime that we shall shortly advance, see Ho (n 3). 
the target would not have committed any token of that type of crime. Thus, the approach cannot allow for the possibility that a target might be entrapped into committing a token crime different tokens of whose type the target was already inclined to commit. For example, the target might be disposed to commit crimes of a certain type, but not ones judged too risky. By contrast, we think that it is clearly possible that the target could, in theory, be entrapped into committing a risky token of this type of crime, by, say, the promise of great monetary reward. We agree with Stitt and James that precluding this possibility is a logically undesirable feature of the appeal to type-crimes in counterfactual conditions. ${ }^{6}$

The type/token distinction is also relevant to the contention that legal entrapment is objectionable because it creates crime. ${ }^{7}$ In the context of entrapment, creation is to be understood, we take it, in terms of the creation of token crimes. Since a type of act can be illegal even if no one in fact ever happens to commit it, type crimes are neither created by, nor depend on, token crimes. For example, there is such a type of crime as murder, even if no-one ever in fact commits a murder, as long as a legislature outlaws it. ${ }^{8}$

Regardless of the account of creation that is adopted, the incoherence objection to entrapment must rest on the contention that it is incoherent for law-enforcement agents (or their deputies), in their official capacities, to aim to create token crimes. In the literature, the counterfactual account of the creation of crime is popular. ${ }^{9}$ According to it, agents create token

\footnotetext{
${ }^{6}$ Stitt and James (n 5, 1984) 114-5.

${ }^{7}$ Some theorists that endorse this objection add that to entrap is to create, rather than to detect, crime. We shall shortly explain their view, and why we disagree with that element of it.

${ }^{8}$ A natural-law theorist would adopt the stronger position that actions like murder are still crimes even if no legislature actually outlaws them.

${ }^{9}$ E.g., Dworkin (n 3) 21, Stitt and James (n 5, 1984) 114, Ho (n 3) 74. Counterfactual accounts of the creation of crime appear (as in the case of Ho (n 3)) to be localized versions of the more general strategy of attempting to account for causation in counterfactual terms.
} 
crimes if the token crimes would not have occurred but for their actions. This does not seem to be the right way in which to understand the creation of a token crime.

The analysis of creation in terms of the 'but for' counterfactual drains the notion of the creation of token crimes of the applicability that it is presumably intended to have when it is invoked in an attempt to advance the incoherence objection. That without which an act could not have occurred is not (even if itself an act) to be confused with the thing that happens to have brought it about. ${ }^{10}$ (Token crimes would not have occurred but for all manner of things: but for the existence of the criminal, but for the existence of the criminal's parents, but for the existence of the victim, but for the meeting of the victim's parents, and so on.)

The notion of creation as we understand it must also be distinguished from that of having acted in a manner that, even if not necessary to the target's commission of the token crime, made the target's act more likely than would otherwise have been the case. ${ }^{11}$ In a decoy operation, the actions of the law-enforcement agents make more likely the target's commission of the token act, and thus the situation meets the condition just mentioned. The actions of an agent posing, during a decoy operation, as a potential victim of a type of crime do not thereby amount to actions that, if a token crime is in fact committed against that agent, mean that the agent created the crime. If creation were to be understood so widely, then the incoherence objection would not be to entrapment per se. Instead, it would be a wider objection, to all forms of proactive law-enforcement that involve the active presentation to the target of an opportunity to commit a crime. We hold that creation goes beyond the mere presentation of an opportunity. On our account, to have created a crime is to have procured it. Entrapment involves the

\footnotetext{
${ }^{10}$ See further (n 1) REF.

${ }^{11}$ By 'more likely' we intend to suggest an act that raises the probability to something less than 1 but greater than 0.5 .
} 
procurement of the actual commission of a crime, rather than mere presentation of the opportunity to commit that crime. ${ }^{12}$

Let us explain the account of procurement with which we are working in condition (iii). For an agent to procure a target's act is, we stipulate, for the agent to influence the target's will through responsiveness, on the target's part, to the content of a communicative act, or series of such acts, on the part of the agent. These communicative acts (which need not be spoken or written and can, for example, be gestural) persuade, solicit or incite the target. ${ }^{13}$

The considerations in this section, along with our account of procurement, lead us to the following conclusion about how the notion of creation, as it features in the incoherence objection, is to be understood. For the agent to create a crime is for the agent to procure an act, on the part of the target, that constitutes a token crime. In procuring an act of a criminal type, the agent influences the target's will (via the agent's communicative act(s)) in order to bring about that act.

\footnotetext{
${ }^{12}$ For a different view, on which both entrapment and creation are conceived of more loosely, see Miller and Blackler (n 3) 107. On their conception, the mere presentation of an opportunity, such as leaving cash somewhere in the hope that the target will steal it, can count both as an act of creation and as one of entrapment. In our view the intentional presentation of an opportunity does not count as entrapment if it is not done with the intention that the target actually commit the crime. Andrew Ashworth seems to have a similar view: he writes 'If test purchases are acceptable, they should be excluded from the definition of entrapment', 'What is Wrong with Entrapment?' [1999] Singapore Journal of Legal Studies 293, 297.

${ }^{13}$ The account of procurement in the law of England and Wales is somewhat broader. In Attorney General's Reference (No. 1 of 1975) [1975] EWCA Crim 1, [1975] QB 773, Lord Widgery defined procurement as follows: 'To procure means to produce by endeavour. You procure a thing by setting out to see that it happens and taking the appropriate steps to produce that happening.' (Attorney General's Ref. 779F). He allows to qualify as procurement of drink driving the surreptitious lacing of a drink without the driver's knowledge. On our account this would not qualify as an example of procurement, unless the agent were encouraging the driver to drink the laced liquid. For more on the view that procurement and causation are distinct, see (n 1) REF.
} 


\section{Interpreting the Incoherence Objection}

There appear to be two broad ways of appealing to the notion of incoherence in relation to entrapment. ${ }^{14}$ The first focuses on the conduct of law-enforcement officials and it stays within the confines of the practice of law-enforcement. The second focuses on the workings of the criminal-justice system as a whole. It concerns the integrity of the criminal process leading from the pre-trial phase (law-enforcement/policing) to the eventual criminal trial. On the second approach, it is held that entrapment is a wrong or failing committed at the pre-trial stage, which renders incoherent the process of arrest, prosecution, and conviction of the target. ${ }^{15}$ The underlying motivation for this assertion, often defended in the form of the 'integrity principle', is that the criminal-justice system is composed of different parts that have to cohere with each other. ${ }^{16}$ Entrapment, when taken to be a wrong perpetrated at an early phase in the criminal process, would introduce incoherence between the different parts of the criminal-justice system and thereby damage its integrity: for the courts, so the argument goes, would not have proper standing to pass judgment on a defendant on the basis of a pre-trial investigation marred by the wrongful act of entrapment.

${ }^{14}$ For a summary of various objections, both legal and moral, to entrapment, see Jeffrey W. Howard, 'Moral Subversion and Structural Entrapment' (2016) 24 Journal of Political Philosophy 24, 25-28.

${ }^{15}$ See Andrew Ashworth, 'Re-drawing the Boundaries of Entrapment' [2002] Criminal Law Review 161; Antony Duff, Lindsay Farmer, Sandra Marshall and Victor Tadros, The Trial on Trial, Volume 3: Towards a Normative Theory of the Criminal Trial (Hart 2007) 242-7.

${ }^{16}$ For more on the 'integrity principle', see Andrew Ashworth, 'Exploring the Integrity Principle in Evidence and Procedure' in Peter Mirfield and Roger Smith (eds), Essays for Colin Tapper (Butterworths 2003); 'Further Notes on Coherence in Criminal Justice' in Petter Asp, Carl E. Herlitz and Lena Holmqvist (eds), Flores Iuris et Legum: Festskrift till Nils Jareborg (Iustus 2002); Andrew Ashworth and Mike Redmayne, The Criminal Process (OUP 2010); Jill B. Hunter, Paul Roberts, Simon N. M. Young and David Nixon (eds), The Integrity of Criminal Process: From Theory into Practice (Hart 2016). 
Despite its apparent clarity, there are many questions to be asked about the integrity-based interpretation of the incoherence objection. ${ }^{17}$ Our focus, however, will be upon the first kind of incoherence charge. Here the waters are much murkier. In particular, the exact nature of the alleged incoherence is, based on what has been written on the topic so far, difficult to grasp. Moreover, the objection is formulated, by those that advocate or mention it, in various ways that are apparently not all equivalent to each other.

In this and the next section, we demonstrate that existing accounts of the incoherence objection (henceforth confined to the first approach) are diverse, and that, particularly over the question of the nature of the purported incoherence, they are far too imprecise. We aim to render more precise the various versions of the objection that are in the literature as well as some versions that, while absent from the literature, are interesting theoretical possibilities. To do so, we begin by considering Gerald Dworkin's advocacy of the objection. Probing the objection as it appears in his work enables us eventually to settle on a new and relatively precise specification of the objection. We then argue that, from among the various interpretations of the objection that we canvass, this specification best maximizes the objection's plausibility.

\section{A. Dworkin's Incoherence Objection}

\footnotetext{
17 There are, perhaps, two obvious questions to ask: in what does the wrongfulness of entrapment consist, and why should we accept the integrity principle? On the latter, the previous footnote provides relevant references. On the former, generally speaking, the integrity principle has two parts: one that uses moral coherence (hence the 'wrong' spoken of is of a moral kind) and another that uses coherence without the qualifier (hence the 'wrong' spoken of is of a non-moral kind). Entrapment is normally considered in connection with this second part, the failing being that entrapment creates crime (instead of, as we explain later, preventing it). See Duff et al. (n 15).
} 
Dworkin's version of the incoherence objection appeals to the notion of the creation of crime and, more specifically, to that of criminal procurement. ${ }^{18}$ His initial statement of the objection appears to be relatively clear:

the law is set up to forbid people to engage in certain kinds of behavior. In effect it is commanding 'Do not do this.' $[\ldots]$

But for a law enforcement official to encourage, suggest, or invite crime is to, in effect, be saying 'Do this.' It is certainly unfair to the citizen to be invited to do that which the law forbids him to do. But it is more than unfair; it is conceptually incoherent. ${ }^{19}$

This passage gives the impression that the incoherence is a case of utterance contradiction. Two utterances are contradictories when one is the negation of the other. Among utterance contradictions, we may distinguish between statement (or assertion) contradiction and (unconventionally, but usefully in the context) command contradiction. A contradictory pair of statements (or assertions) cannot be true together and cannot be false together. If two statements (or assertions) are in contradiction, then exactly one of them is true. A contradictory pair of commands, requests or bans cannot both be complied with, or both be flouted, by the same agent at the same time. If two commands are in contradiction then for any given agent at a given time, the agent is compliant with exactly one of them. ${ }^{20}$ While Dworkin appears to depict the incoherence at issue as a form of command contradiction, his suggestion readily

\footnotetext{
${ }^{18}$ Dworkin (n 3) 30-34.

${ }^{19}$ Dworkin (n 3) 32.

${ }^{20}$ It does not follow that the agent is obedient to exactly one of them. Obedience involves complying for the right reason. As Robert Paul Wolff puts it, 'Obedience is not a matter of [merely] doing what someone tells you to do. It is a matter of doing what he tells you to do because he tells you to do it', In Defense of Anarchism (2nd edn, University of California Press 1998) 9, italics original.
} 
lends itself to construal, as follows, as involving a deontic-logical statement contradiction. On this construal, when the agent entraps, the agent suggests that the entrapped act is permissible. Given that the law debars acts of that type, the law logically implies the impermissibility of the entrapped act. Thus, what the agent suggests about the permissibility of the type act contradicts what the law implies about that permissibility. This statement-contradiction interpretation, however, suffers from the flaw that the attempted (or successful) procurement of a token act of a criminal type need not (and typically will not) involve any communicative act (or series of such acts) on the agent's part such that its content implies the legal permissibility of the entrapped act. The entrapping agent will typically not be concerned to convey any message, or impression, to the target that the entrapped act is not illegal. Would a command-contradiction interpretation fare better? It would not, and for a similar reason. The procurement of a token act of a criminal type involves having a certain kind of influence, as explained in section 2 above, on the will of the target. To command the target to commit the act is only one of many ways in which to attempt (or to achieve) this. So, to attain a plausible conception of the sort of incoherence involved in Dworkin's version of the incoherence objection, we require a notion weaker than command contradiction.

In any case, in so far as our concern is with understanding wherein, precisely, the supposed incoherence of legal entrapment lies on Dworkin's account, the above quotation sets us off, according to Dworkin's own subsequent remarks in the piece, on the wrong path. While the quotation suggests an utterance-contradiction account of the alleged incoherence, Dworkin almost immediately announces that the incoherence objection is not to be construed this way. The piece, however, then characterizes the incoherence that is supposedly involved only in negative terms, leaving us none the wiser as to wherein, exactly, the supposed incoherence of 
legal entrapment lies. ${ }^{21}$ A possible escape route from this situation emerges from a little more reflection on the command-contradiction interpretation. Given that the act that the agent intends the target to perform is of a criminal type, it is an act of a type that is legally prohibited. Thus, the law commands that it not be performed. The agent's communicative act (or series of such acts) of procurement is intended to encourage the target to perform the act. It expresses an intention, on the agent's part, that the target break the law. It is the agent's intention and the law's requirement that fail to cohere with each other: for the target cannot simultaneously satisfy them. ${ }^{22}$

We offer this observation as a way of trying to convert Dworkin's incomplete, and wholly negative, characterization of the relevant form of incoherence into something more precise. We believe, and argue over the course of this article, that the best prospects for the incoherence objection lie in the appeal to the notion of practical incoherence. In order to cast the objection in its best light, proponents of the incoherence objection ought to allude not to a formal or utterance contradiction or contrariety, ${ }^{23}$ but rather to the notion, recognized by Aristotle and within the Aristotelian philosophical tradition, of contrariety of ends. Two ends, such as enforcing a party's observance of a law and encouraging that same party to disobey that law, are contraries when the attainment of one of them by an agent necessarily precludes the simultaneous attainment, by the agent, of the other.

\footnotetext{
${ }^{21}$ Dworkin (n 3) 32-33. Dworkin's negative characterization of the incoherence consists in the denial that it involves either a 'literal' or a 'pragmatic' contradiction.

${ }^{22}$ Dworkin (n 3$) 32$ remarks that 'it is not the purpose of officers of the law to encourage crime' and he holds, further, that it is contrary to their purpose for them to do so. Thus, we take his to be what we shall call a 'functional' version of the incoherence objection.

${ }^{23}$ The difference between an utterance contradiction and an utterance contrariety is that an utterance contradiction occurs when the two utterances cannot both be true and cannot both be false, whereas an utterance contrariety occurs when they cannot both be true, thus leaving it open that they are both false.
} 
This is, however, still not precise enough. In particular, we still need to get a grip on exactly wherein the aforementioned contrariety of ends consists: what exactly are the entrapping agent's contrary ends? We can get to an answer by noticing, first, that Dworkin's ultimate position does not seem to be that entrapment is always incoherent. Instead, he appears to hold that incoherence enters the picture when (but only when) law-enforcement agents attempt to entrap an individual that they do not have good reason to believe is already engaging in acts of the same type as the intended token criminal act. ${ }^{24}$

Dworkin claims that random entrapment involves creating, rather than detecting, crime. ${ }^{25}$ On his account, to entrap an agent that has not already been committing (or intending to commit) crimes of a given type, $\mathrm{C}$, is to create a token crime that manifests neither prior nor ongoing criminal conduct (or intended conduct) of the same type. Dworkin appears to hold that to entrap into committing an act of type $\mathrm{C}$ a target that is already engaged in (or intending to engage in) criminal conduct of type $\mathrm{C}$ counts as genuine detection (rather than creation of crime). It seems, then, that, for Dworkin, creation of crime occurs when a target is entrapped into committing a crime that is of a type none of whose tokens the target was already engaged in committing (or intending to commit). Dworkin's ultimate position is that it is the use of entrapment against people that are not already suspected of committing crimes (or of intending

\footnotetext{
${ }^{24}$ Dworkin (n 3) 33. We use hesitant language in making this statement about Dworkin because our interpretation of what he says relies on connecting incoherence to impermissibility. We reason that if Dworkin thought that entrapment were always incoherent then, plausibly, he would think it impermissible in all circumstances too. Instead, his position appears to be that entrapment is impermissible only in the cases he calls 'virtue testing'. Ultimately, though, whether we are right in our interpretation of Dworkin makes no difference to the cogency of our argument. Note also that we use the phrase 'virtue testing' in a very different way from Dworkin; we use it to refer to the intentional presentation by the agent to the target of the opportunity to commit a crime where the agent does not intend that the target actually commit the crime.

${ }^{25}$ Dworkin (n 3) 33. Cf. Sherman v United States, 356 US 369, 384 (1958), concurring judgment.
} 
to commit crimes) of the relevant type that is incoherent: for, on Dworkin's view, creation is inconsistent with detection, and detection, but not creation, is a legitimate aspect of law enforcement. In short, the contrary ends for which we have been looking on the part of the entrapping agent are those of detection (of crime), on the one hand, and of creation (of crime), on the other. There is a question, however, whether it is really detection with which such cases of the creation of crimes are to be held inconsistent.

Recall that, on our account, when an agent procures a crime the agent has influence of a certain sort on the target's will. To procure a crime is, we stipulated, to bring it about through solicitation, persuasion or incitement, that another commits that crime. Acts of solicitation, persuasion and incitement are communicative acts: these include, but are not restricted to, speech acts. ${ }^{26}$ To have procured a crime that a target has committed is to have inclined, via the content of such a communicative act, or series of such acts, the target's will towards committing that token crime. Now, although a target may be already inclined to commit a crime of a given type, it is nevertheless possible for an agent to entrap such a target: a will that is generally disposed to committing crimes of a certain type need not be inclined on every single occasion when an opportunity to commit such a crime with an apparently low risk of being caught is presented, to take up that opportunity. In fact, even a record of convictions for crimes of a given type is strong evidence only of predisposition to commit crimes of that type: it is not the case that, for every relevant token of that type, it is strong evidence of a predisposition to commit

\footnotetext{
${ }^{26}$ Flagging down a taxi, for example, is a communicative act that is not a speech act. In this respect, it differs from a gesture of a sign language such as British Sign Language. The gestures of BSL are part of an overall system of communication that possesses both a syntax and a semantics. It seems to us that this cannot be said of such gestures as flagging down a taxi, waving or giving the thumbs up, at least when these gestures are not parts of an overall system of communication in which the symbols involved are type homogeneous (e.g., they are all inscriptions, or phonemes, or gestures) and in which there are formation rules for strings of them.
} 
that token. It is therefore unclear whether the incoherence objection can really be restricted, as Dworkin seeks to have it, to cases where the target was innocent of the type crime prior to the entrapment scenario.

Let us clarify this further by providing a more formal representation of Dworkin's position. Dworkin seems to appeal to the following principles:

1. When legal entrapment occurs, the target is either already reasonably suspected of engagement, or of intending engagement, in crimes of the same type as the token entrapped crime, or not so suspected.

2. If the target is not so suspected, then the agent is creating, or attempting to create, the token crime (whether or not it is traced to the target). ${ }^{27}$

3. If the target is so suspected, then the agent is detecting the token crime (on the assumption that it is traced to the target).

4. The agent cannot both detect and create (or even attempt to create) one and the same token criminal act.

5. Creation (and attempted creation) and detection are contrary functions: thus, the creation (or attempted creation) of a crime by law-enforcement agents is inconsistent with their role of detecting crimes.

The fundamental problem we see here is that Principle 4 is false: it is possible to detect and create one and the same token criminal act. When agents entrap, they help to create a token crime. They may also find evidence that links the target to the crime, in which case they detect

\footnotetext{
${ }^{27} \mathrm{It}$ is possible that the target, unknown to the agent, is engaging in crimes of the same type as the token entrapped crime. In this case the agent is not, according to this principle, creating the crime but attempting to create it.
} 
it too. If creation and detection are contrary functions, then this is not because it is impossible both to create and to detect the same token act of a criminal type- on the contrary, doing this is clearly possible. We conclude, therefore, that the incoherence objection cannot succeed if it appeals to the alleged incompatibility of creation and detection at the level of the target's token act.

To make the incoherence objection work, we need, then, to find some other contrariety in the agent's ends. Let us go back to our original idea: it is the agent's intention that the target should perform an illegal act and the law's injunction against that act that are incompatible, for the satisfaction of one necessarily precludes the simultaneous satisfaction of the other. Dworkin's incoherence objection, when interpreted in the most charitable way, consists, we take it, in the assertion that the function of law enforcement is incompatible with, and therefore subverted by, satisfaction of the entrapping agent's intention. Since, as we understand the concept of entrapment, it is impossible to entrap without having that intention, entrapment itself is functionally incompatible with law-enforcement.

The underlying incompatibility, we suggest, is not between creation and detection, but between creation and prevention. Since it is impossible for an agent both to prevent and to create a given token crime, but possible for that agent to do neither, we are dealing with a form of contrariety rather than a form of contradiction. Agents that procure a token act of a criminal type create it and have intended to create it. They have not intended to prevent it. The law expresses the intention that the act should not occur, while the act of entrapment expresses the intention that it should.

Nevertheless, the incoherence objection is too strong if interpreted like this. Lawenforcement agents do not have a duty to prevent every crime that they possibly can. There will certainly be many occasions when law-enforcement agents have to choose between preventing two crimes, with the result that there is one crime that they do not prevent, even 
though they could have done so. It would be incorrect to suggest that the law-enforcement agents are engaging in incoherent conduct, or even are guilty of dereliction of duty, if they intentionally allow a minor crime to occur in order to prevent a major crime. It may even be that the law-enforcement agents allow a minor crime for the sake of the possibility of preventing a major crime, as when they allow the boss's minion to get away with something small in order that they might find out who the boss is.

Can this line of argument be employed concerning creation of token crimes, rather than permission of them? When law-enforcement agents entrap, they intend to create a crime, but for similar reasons to those already discussed: they intend to prevent a future crime or crimes by arresting the target and preventing the target from committing further offences. Or it might be that they intend to create a crime in order that the target might be punished for previous offences: perhaps when the target is under lock and key witnesses may be able to identify the target as the culprit behind other unsolved cases. The law-enforcement agent has the general aim (among others) of preventing crime or upholding the law: there are situations in which to reduce the overall amount of crime by the greatest amount the agent may have to create a small amount.

How can the proponents of the incoherence objection respond? One way is to accept the above and restrict the objection to just those cases of entrapment where there is no long-term aim of preventing crime. We think, however, that most proponents of the objection intend it to apply to all cases of entrapment; besides, it would make the objection more interesting and powerful if its scope were not restricted. What can its proponents say, then?

They could take a Kantian-style position that law-enforcement agents have a duty never to create crimes, and that this duty can never be suspended for any higher purpose. Although this means that there may be more crime in a state than there otherwise would be, blame for this regrettable fact is not to be laid at the feet of the law-enforcement agents. Rather, it is a potential 
side-effect of any theory that denies that an action can always be justified if the consequences are good enough. ${ }^{28}$

We are not here attempting to answer the moral question of whether entrapment is ever permissible. We are merely seeking to show what must be believed in order for the incoherence objection to work. If the objection is to encompass all cases of legal entrapment, then we believe that it must involve the assertion that law-enforcement agents have an absolute duty never to create crimes.

\section{B. Summary, So Far}

In the course of our discussion of Dworkin, we have come across the following forms of incoherence and weighed each of them up as an interpretation of the alleged incoherence. ${ }^{29}$

Statement contradiction. According to this interpretation, when agents entrap they declare that a type of action that is legally debarred is, in fact, legally permissible. This is not a

\footnotetext{
${ }^{28}$ For further illustration of the strictness of the duty, its demands clearly spill over to undercover work. Take the case of an undercover officer that witnesses or even contributes to crimes, but does so in order to avoid blowing their cover. The Kantian duty, it seems, would also not allow this behaviour and, since undercover work is likely to involve such instances of permitting or even helping others to commit crimes, the Kantian duty would (severely) restrict (if not eliminate) undercover work.

${ }^{29}$ We do not claim that these interpretations exhaust the possibilities. For example, it might be claimed that the entrapping agents' utterances are contrary to one of the agents' law-enforcement functions, or that it is the utterances of the judge and/or the prosecution, if the case gets to court, that are contrary to those of the agents. We admit that these possibilities, among others that we have not discussed, are in principle available (although some of them, including this example, are covered by our setting aside of the integrity-based form of the objection). We have concentrated on what we take to be the more plausible candidate interpretations of the incoherence objection.
} 
charitable interpretation of Dworkin's objection, because it is untrue that entrapping agents must make, or even suggest, any such declaration.

Command contradiction. This interpretation has it that, when entrapping, agents enjoin the targets to commit acts that are of a type the criminal-justice system enjoins people not to commit. While perhaps more plausible than statement contradiction, this objection is also based on an exaggerated generalization. Entrapping agents need not go so far as to enjoin the targets to commit the acts. If the targets' acts have been procured by solicitation, persuasion or incitement on the agents' part, then it does not follow that the agents have specifically enjoined the targets to commit them: even if incitement is constituted by, or involves enjoining the targets to commit the acts, solicitation and persuasion can be subtle forms of encouragement that need not involve going so far as enjoining the targets to commit the acts. For example, a communicative act that is intended to 'nudge' the target, and succeeds in doing this, can procure the act.

The two forms of contradiction listed so far are both cases of utterance-contradiction. This provides what is the strongest form of the incoherence objection from a logical point of view, but which is consequently the weakest in terms of philosophical credibility. When two utterances contradict each other, this situation cannot be changed by the addition of further utterances. It could easily be written in statute that, while it were a criminal offence for civilians to abet or encourage someone in committing a crime, the police might do so in the context of attempting to bring someone to justice. If the incoherence objection had to be interpreted as involving an allegation of utterance contradiction, then it would be utterly implausible. Moreover, other, more plausible, interpretations are available. Thus, no utterance-contradiction interpretation should be adopted.

Functional contrariety/contrariety of ends. When agents entrap, they pursue an end (the encouragement of targets to commit crimes) that cannot be pursued (by the same agents) at the 
same time as their end of enforcing the law. The agents create token acts of a criminal type, and this is contrary to the end of preventing such acts. The latter end, in turn, is one that the agents have, whether it is present to their minds or recognized in their actions and intentions, in virtue of their offices as law-enforcement agents. It is part of the functional role of law enforcement to prevent, and so not to create, acts of a criminal type. This is the interpretation of Dworkin's version of the incoherence interpretation that we have suggested is the most plausible. Unlike earlier candidates, this interpretation does not appear to rest upon a false empirical generalization about the behaviour of entrapping agents. In order for the objection to apply to all cases of legal entrapment, however, it has to supplemented by a Kantian-style thesis that this role can never be suspended in the short term for the sake of a long-term gain in crime prevention.

\section{Other Formulations of the Incoherence Objection}

We have argued that the most plausible construal of Dworkin's version of the incoherence objection involves the idea that law-enforcement agents engaged in entrapment will lapse into a form of practical incoherence involving contrariety of ends. The objection rests on, we have suggested, the proposition that law-enforcement agents have an absolute duty never to create crimes. In this section we survey formulations of the incoherence objection in the work of writers other than Dworkin. Our purpose now is to assess whether any of these fares better than the version of the objection that we specified, via our probing of Dworkin's account, in the previous section. We argue that this is not the case. Each such formulation either does not give us a readily workable version of the objection or is best interpreted as a less precise way of stating the objection in the form given in the previous section.

\section{A. Ashworth's Incoherence Objection}


Andrew Ashworth is another prominent supporter of the incoherence objection. ${ }^{30}$ The following remarks suggest a version of the objection:

[When entrapment occurs] the entrapping officer has breached the internal rules of the police or other law enforcement agency, and may well have committed a crime. Entrapment will usually involve the inchoate offence of incitement, and may make the entrapper an accomplice to the substantive offence as a counsellor or even a procurer. The English Law Commission went so far as to suggest that there should be a specific crime of entrapment, which an officer would commit if he incited the commission of an offence and even if he intended that the completion of that offence would be prevented or nullified. ${ }^{31}$

There are several suggestions in play here. We rephrase them in our own language, and by reference to the account of legal entrapment given in section 1:

Rule breach: a law-enforcement officer that engages in entrapment breaches the internal rules of the officer's law-enforcement agency.

Criminality through complicity: to procure a crime involves being complicit as an accomplice to the crime; entrapment involves procurement; so, entrapment involves criminal complicity.

\footnotetext{
${ }^{30}$ Ashworth (see especially the works cited in $\mathrm{n} 16$ ), is also a supporter (in fact, perhaps the most prominent and explicit supporter) of the integrity-based form of the objection, which we set aside at the start of the previous section.

${ }^{31}$ Andrew Ashworth (n 12) 310-11. See also Ashworth (n 15): notes 36-8 focus in particular on the contention that legal entrapment involves criminality on the part of the agent; for more on this see also Glanville Williams, Criminal Law: The General Part (2nd edn, Stevens 1961) 781-2.
} 
Criminality through encouragement or assistance: ${ }^{32}$ usually, entrapment involves encouragement or assistance to commit a crime; encouragement or assistance to commit a crime is itself a crime.

Each of these suggestions can be construed as providing a reason why legal entrapment might be considered, at least under certain circumstances, incoherent.

If rule breach is intended as an empirical generalization, then it is easily seen to be false. There are law-enforcement officers in certain jurisdictions, such as China, in which neither the law-enforcement agency itself nor the law proscribes entrapment as being against the rules or a form of misconduct. ${ }^{33}$ Moreover, this goes not just for formal rules, but also for informal rules that are matters of 'custom and practice', or matters of 'ethos' without being formally codified or documented. ${ }^{34}$

Rule breach appears more plausible when interpreted, rather than as an empirical generalization, as making the same essential point as Dworkin's 'functional' version of the incoherence objection. On this construal, it is a rule internal to the practice of law-enforcement that law-enforcement does not involve entrapment. ${ }^{35}$ This is for the subsidiary reason, not

\footnotetext{
${ }^{32}$ Ashworth, writing in 1999, uses the term 'incitement', but the offence of incitement was abolished in England and Wales in 2008 under the Serious Crime Act 2007 s. 59.

${ }^{33}$ See Sijia Zhou, 'Research on Entrapment in China-With Reference to the Experience in Canada' (LLM

Thesis, McGill University, 2013)<http://digitool.Library.McGill.CA:80/R/-?func=dbin-jumpfull\&object_id=121597\&silo_library=GEN01> accessed 4 January 2019.

${ }^{34}$ Cf., for the distinction, Fred D'Agostino, 'The Ethos of Games', (1981) 8 Journal of the Philosophy of Sport 7. ${ }^{35}$ One might be tempted to construe this rule as a 'practice rule' in John Rawls's sense (in his 'Two Concepts of Rules', (1965) 64 Philosophical Review 3). As we note below, however, it is perfectly possible to conceive of a law-enforcement agency with the sole function of investigating crime. Hence, this rule cannot be taken to constitute the practice of law-enforcement as Rawls would have it.
} 
stated, but implicit in the above statement of rule breach, that to entrap is to procure a token crime, which procurement is incompatible with the function of law-enforcement, as this latter involves preventing, not creating, (token) criminal acts. Since rule-breach is intended as a general injunction that debars all acts of legal entrapment on the grounds of their alleged incoherence, it must appeal to a factor that is common to all cases of legal entrapment. We have already argued that it is not the breach rules, whether formal or informal, that is this common factor. In identifying procurement as the common factor, we are able to advocate, to some extent, on Ashworth's behalf.

There is another drawback, however, with rule breach as Ashworth states it. This is that it is too narrow to construe rule breach, as he does, as happening when an entrapping lawenforcement agent's conduct is inconsistent with the rules of the law-enforcement agency to which the agent belongs, or, as we prefer, as inconsistent with a principle internal to the practice of law-enforcement. To see this, note that a law-enforcement agency could be established whose sole function was to investigate crime, and perhaps also prosecute the perpetrators, with law-enforcement's other functions being carried out by other agencies. ${ }^{36}$ There seem to be no rules internal to the practice of investigating crime that debar the creation of token crimes. This drawback can be remedied by widening the sort of rules involved. A very wide way of doing this would be to include all and only those rules that are internal to those functions that the practice of law-enforcement in general has, rather than to any particular branch of it or agency responsible for it.

As a result of the above discussion, a full argument can now be reconstructed based on considerations inspired by the above quotation from Ashworth:

\footnotetext{
${ }^{36}$ Perhaps the Serious Fraud Office in the UK is an example of such a law-enforcement agency; compare the 'Statement of Principle' at <www.sfo.gov.uk/publications/guidance-policy-and-protocols/\#statement> accessed 4 January 2019.
} 
1. It is a rule internal to the practice of law-enforcement (as a whole) that law-enforcement agents do not create token crimes. (Premise)

2. Whenever law-enforcement agents entrap those not intending to commit the crime in question, they create token crimes. (Premise)

3. Whenever law-enforcement agents entrap those not intending to commit the crime in question, they breach a rule that is internal to the practice of law-enforcement. (From $1,2)$

4. To breach a rule that is internal to a practice in which one is involved is to engage in conduct that is incoherent. (Premise)

5. Whenever law-enforcement agents entrap those not intending to commit the crime in question, they engage in conduct that is incoherent. (From 3,4)

The main flaw in this argument seems to be Premise 4. Let us give an example different from entrapment: can law-enforcement agents exceed speed limits and go through red lights at junctions when in pursuit of a dangerous criminal? The Police Federation of England and Wales once issued a letter that said:

Police officers have a sworn duty to uphold the law and they must comply with that duty.

They must also act in a way which is lawful. [...]

A typical response or pursuit drive is likely to involve the officer contravening traffic signs and or speed limits. A course of driving involving contravention of traffic signs and speed limits is very likely to fall within the definition of careless or dangerous driving. [...] There 
are no legal exemptions from the offences of careless or dangerous driving. Any such drives are therefore likely to be unlawful[.. $]^{37}$

The correctness or otherwise of the legal statements in this letter is not our concern. ${ }^{38}$ What is of interest is that it seems to appeal to something like the incoherence objection: that the police know that they have a duty to uphold the law, and that, therefore, it is incoherent for them intentionally to break the law. Now consider a police officer that responds to the letter by saying 'it's more important that I prevent a major breach of the law by catching a dangerous criminal than that I refrain from a minor breach of the law by not running this red light, so that's what I intend to do' ${ }^{39}$ Is this response incoherent? Premise 4 says that it is. It seems to us, however, that this can be maintained only if Ashworth adopts a strong Kantian stance to the effect that the duty of police officers to uphold the law is always and everywhere inviolable.

Let us now turn to Ashworth's other suggestions. Criminality through complicity can also be developed into a more substantial argument, as follows:

1. Upholding the law is a general end/function of law-enforcement. (Premise)

37 Tim Rogers, letter of the Police Federation of England and Wales (26 June 2017) <www.polfed.org/documents/Driver_Advice_Final_Letter_5_2017_(3).pdf $>$ accessed 5 January 2019 (emphasis original).

${ }^{38}$ It should be noted that, under the Road Traffic Regulation Act 1984, s. 87, speed limits do not apply to police vehicles being used for police purposes (in England and Wales), and, under The Traffic Signs Regulations and General Directions 2002, s. 36, red lights do not apply to the emergency services in the same manner in which they apply to the general public.

${ }^{39}$ Compare this news story from Switzerland: 'Swiss Policeman Fined for Speeding during High-Speed Chase' (The Local, 29 January 2019) <www.thelocal.ch/20190129/swiss-policeman-fined-for-speeding-during-highspeed-chase $>$ accessed 16 February 2019. 
2. Every act of entrapment is an act that procures a token crime. (Premise)

3. For every token criminal act that one procures, one is an accomplice to that token criminal act. (Premise)

4. To be an accomplice to a token criminal act is to act criminally. (Premise)

5. To act criminally is to fail to uphold the law. (Premise)

6. Whenever a law-enforcement agent entraps, the agent is an accomplice to a token criminal act. (From 2, 3)

7. Whenever a law-enforcement agent entraps, the agent acts criminally. (From 4, 6)

8. Whenever a law-enforcement agent entraps, the agent fails to uphold the law. (From 5, 7)

9. Whenever a law-enforcement agent entraps, the agent's conduct is contrary to a general end/function of law-enforcement. (From 1, 8)

Again, the defender of entrapment is likely to respond that it is permissible to act contrary to the general end in one way if one ends up serving it (or even likely to serve it) in another way: in consequence, creation of a small crime may be justified in pursuit of prevention of a big crime or more than one crime. Once more, then, it seems that Ashworth must, if his version of the incoherence objection is to hold across all cases, adopt a strong Kantian-style stance that the end of upholding the law can never legitimately be breached in the short term in order to be achieved more thoroughly in the long term.

When rule breach and criminality through complicity are spelled out in their more developed versions above, the differences between them emerge as minimal. Crucially, they both rely upon the contention that entrapment is incoherent because it is contrary to a general function/end of law-enforcement. The main difference between the two arguments is that criminality through complicity goes further than rule breach in that it also alleges a form of 
criminality. This additional aspect of criminality through complicity (and the correctness of the corresponding grounding premises in the argument), however, is immaterial to our dialectical purposes in this paper.

If the reference to incitement here is replaced by a reference to procurement (which includes, but is not limited to, incitement), then the resultant objection, criminality through procurement, extends to every act of entrapment (since, we are assuming, every act of entrapment involves procurement). There is nothing to be gained from advancing criminality through incitement as an objection separate from criminality through complicity, given the greater generality of criminality through complicity. When that same generality is obtained by replacing criminality through incitement with criminality through procurement, the latter appears to be a mere variant of criminality through complicity.

The upshot of our discussion of Ashworth's version of the incoherence objection is that it, like Dworkin's objection, is most plausible when interpreted as resting on the appeal to a form of practical incoherence stemming from a contrariety of ends. Our interpretations of what these two theorists have to say about the incoherence of entrapment are thus in a relationship of mutual support.

\section{B. Howard on the Incoherence Objection}

Jeffrey Howard states the incoherence objection (without endorsing it) as follows: 'the state acts inconsistently when it insists that citizens adhere to the law, but then takes measures to induce them to break it. ${ }^{40}$ On this understanding, the alleged incoherence appears to be between, on the one hand, pronouncements or utterances of the state that citizens must adhere

\footnotetext{
${ }^{40}$ Howard (n 14) 26.
} 
to the law and, on the other hand, actions, on the part of some of its agents, that are designed to encourage some citizens, in some circumstances, to break the law.

Let us survey three ways to interpret Howard's statement of the objection. First, it is familiar, as in the case of people that do not practise what they preach, that the pronouncements of individual agents may be at odds with their own behaviour. A television evangelist, for example, might condemn adultery in public, but practise it in private. This sort of incoherence is hypocrisy. Suppose, that, in virtue of its agents, the state can act. The analogy with the television evangelist is straightforward only if the state, in inducing someone to break the law, thereby does what it itself condemns. In discussing Ashworth's criminality through complicity, we saw that this might be the case, but it is not necessarily so: the special responsibilities of law-enforcement agents come with a certain amount of special licence that they have in virtue of their offices as law-enforcement agents.

Howard's exact formulation of the charge speaks not of the state's breaking the law, but of the state's encouraging its citizens to break the law. This suggests - and this leads us to our second interpretation of Howard's formulation - that the incoherence, if any, of legal entrapment is not like that of the television evangelist mentioned earlier. Rather, it is more like that of a television evangelist that preaches against adultery but, without committing it, intentionally tempts someone else to do so, with the aim that this person will succumb to the temptation. Now, intentionally to tempt someone, in this manner, to do something that one declares to be wrong (in our case: criminal) might be hypocritical and criminal, as well as morally wrong. Whether it is incoherent, though, is less obvious. ${ }^{41}$

Both the interpretations discussed so far assume that when legal entrapment occurs, it is the state (in virtue of its agents) that is acting. How about giving up this assumption? Doing so

\footnotetext{
${ }^{41}$ For a discussion of the relationship between entrapment and temptation, and its ethical implications, see REDACTED.
} 
leads us to our third interpretation of Howard's formulation. In this case, rather than understanding the incoherence objection in terms of the state's doing something that is inconsistent with its pronouncements, which would involve entanglement in the issue of whether the state is itself an agent, it is perhaps better to view it in the following terms. When law-enforcement agents entrap someone, one group of state agents, namely the lawenforcement officers (who are part of the executive), encourage the target to do something that another group of state agents, constitutive of the legislature, have deemed (in statute) to be legally impermissible or that a third group of state agents, consisting of the judiciary, have deemed (e.g., on the basis of case law) to be impermissible under the law. Read in this way, the incoherence involved in legal entrapment would not be one of hypocrisy focusing on one agent only, but would appear at the level of the criminal-justice system. This interpretation of Howard's statement of the incoherence objection, however, would be reading it as just another, albeit perhaps weaker, formulation of the integrity-based form of the incoherence objection, which we have set aside at the start of our discussion.

\section{Carlson on the Incoherence Objection}

Jonathan C. Carlson asserts that '[f]or the government itself to encourage acts that could actually cause injury to the interests it wished to protect would be the height of absurdity'. ${ }^{42}$ The idea here is that it would cause injury to the interests of the state if someone were selling illegal drugs, say, and that it would, in consequence, be incoherent for the government actually to encourage this injury by having its agent request illegal drugs from the target. But Carlson makes this assertion only to point out that it does not apply to most cases of entrapment: in

\footnotetext{
${ }^{42}$ Jonathan C. Carlson, 'The Act Requirement and the Foundations of the Entrapment Defense' (1987) 73 Virginia Law Review 1011, 1061.
} 
many cases (e.g. when the agent pretends to be an assassin and encourages the target to place an order for someone to be eliminated) the forbidden act does not in fact take place, and the target is arrested for the offence of attempting to procure the forbidden act, and in other cases (e.g. when the agent buys illegal drugs off the target) the forbidden act occurs, but its harm is neutralized (because the drugs are destroyed, rather than consumed, by the agent). Nevertheless, there are some cases of entrapment in which the critique mentioned by Carlson does apply. For example, if an undercover agent encourages some bank robbers to rob a particular bank in which the police will lie waiting the agent may well know that the robbers will cause some harm (physical damage and shock to innocent bystanders) before they are apprehended. (This critique would extend to cases of pro-active policing as well, in which police might watch an area notorious for assaults in the hope of catching an assailant in the act, while knowing that they will not be able to stop the assailant before harm has been caused to the victim.) Although there is a prima facie case here for incoherence ('absurdity' in Carlson's word), once again it seems to us that the argument requires a strong Kantian premise to the effect that it is never permissible to encourage a small injury to the interests one wishes to protect in order to prevent a bigger injury to them. Absent such a premise, it seems to us that the existence of incoherence or absurdity is not made out.

\section{A More Exact Formulation of the Incoherence Objection}

We have argued that the incoherence objection to legal entrapment by law-enforcement agents is best formulated using the distinction between the prevention and the creation of crime. According to the objection, legal entrapment gives rise to a contrariety of ends, and, thus, a prima facie form of practical incoherence. We can now provide a more exact formulation of the incoherence objection, as follows: 
1. The prevention of crimes is a general function of law-enforcement. (Premise)

2. If the prevention of crimes is a general function of law-enforcement, then lawenforcement agents must, on pain of incoherence, neither intentionally bring about, nor intentionally help to bring about, token crimes. (Premise)

3. When an agent entraps a target, that agent intentionally procures a token crime. (Premise)

4. If an agent intentionally procures a token crime, then the agent intentionally brings about, or intentionally helps to bring about, that token crime. (Premise)

5. When an agent entraps a target, the agent intentionally brings about, or intentionally helps to bring about, a token crime. (From 3, 4)

6. Given the general functions of law-enforcement, on pain of incoherence, lawenforcement agents must not intentionally bring about, or intentionally help to bring about, token crimes. (From 1, 2)

7. Given the general functions of law-enforcement, on pain of incoherence, lawenforcement agents must not entrap anyone. (From 5, 6)

On the assumption that the definition of entrapment upon which this argument draws is correct (and hence that Premises 3 and 4 are defensible) and that we are right that the prevention of crime is a general function of law-enforcement (Premise 1), the controversy is likely to centre upon Premise 2. Note that the consequent of Premise 2 is normative, for it states what lawenforcement agents must not do. The key questions concern how the normativity is to be construed, and whether it is absolute.

We think the following story might be told on behalf of proponents of the incoherence objection. The wrongness of practical incoherence, it might be suggested, consists in breach of a requirement of practical reason. But 'requirement of practical reason' is itself interpreted in two different ways, first as requiring structural rationality, i.e. structural requirements on our 
attitudes, and, secondly, as requiring reasons for action. ${ }^{43}$ To take the first of these, is there structural practical irrationality involved in entrapment? There is an argument for that conclusion. Consider the following remarks from Thomas E. Hill, Jnr, on different forms of irrational practical incoherence:

if certain means are necessary to an end, one must choose the means or else give up the end; to hold on to an end while refusing to take the necessary steps to achieve it is a form of practical incoherence. [...] Similarly, it is generally a mark of incoherent (though possible) practical thinking to pursue goals that undermine one's other goals or to employ means that violate the values that were the basis for choosing one's goals. ${ }^{44}$

The first requirement is given by what is called the instrumental principle. This can easily be met, however, by cases of entrapment: there is no reason to suppose that entrapment is not a means, and not chosen as a means, to an end, such as long-term crime prevention.

The other two phenomena that Hill enlists do seem better candidates for the proponent of the incoherence objection, however. When law-enforcement officers entrap, they seem to go against one of the very values (crime prevention), and an associated rule (not to create crimes), central to their roles as law-enforcement officers. Nevertheless, the charge that this amounts to

${ }^{43}$ See R. Jay Wallace, 'Practical Reason', The Stanford Encyclopedia of Philosophy (Spring edn, 2018) $<$ https://plato.stanford.edu/archives/spr2018/entries/practical-reason/>, esp. s. 4, and Niko Kolodny and John Brunero, 'Instrumental Rationality', The Stanford Encyclopedia of Philosophy (Winter edn, 2016) $<$ https://plato.stanford.edu/archives/win2016/entries/rationality-instrumental/>, esp. s. 1. Both accessed 27 December 2018.

${ }^{44}$ Thomas E. Hill, Jnr, 'Reasonable Self-Interest', (1997) 14 Social Philosophy and Policy 52, 68 note 27. 
practical irrationality seems to fall to the response that there is no irrationality in sacrificing short-term crime-prevention for greater crime-prevention in the long-term.

Finally, then, let us consider an approach based on the idea that practical reason consists in requiring reasons for one's conduct. Consider the following remarks from Thomas Scanlon:

Being a good teacher, or a good member of a search committee, or even a good guide to a person who has asked you for directions, all involve bracketing the reason-giving force of some of your own interests which might otherwise be quite relevant and legitimate reasons for acting in one way rather than another. So the reasons we have for living up to the standards associated with such roles are reasons for reordering the reason-giving force of other considerations: reasons for bracketing some of our own concerns and giving the interests of certain people or institutions a special place. ${ }^{45}$

Scanlon's ideas could be applied to form an incoherence objection as follows. Good lawenforcement officers are like good committee members - in virtue of their role, they have reason to do what prevents crime from happening, and, in virtue of the same role, any considerations that might otherwise have counted in favour of creating crime do not so count. ${ }^{46}$ We could then say that entrapment involves a significant practical failing on the agent's part since the agent is no longer responding properly to the balance of reasons in his/her case.- Still, it seems to us that this Scanlon-inspired theory fails in the face of the response that the considerations in favour of creating crime do not cease to count for the agent just because the

\footnotetext{
45 Thomas Scanlon, What We Owe to Each Other (HUP 1998) 53.

${ }^{46}$ Scanlon defines reasons as 'considerations that count in favour of adopting' ( $\mathrm{n} 45$ ) 17. Considerations that are 'bracketed' do not constitute reasons for a particular course of action, since, in virtue of their being bracketed, they do not count in favour of adopting that course of action.
} 
agent occupies a law-enforcement role. They may count for less for the agent than they do for someone that does not occupy a law-enforcement role, but they do still count for something, and, it seems to us, they could count strongly enough to outweigh the considerations against creating crime. The only counter to this response, it seems to us, is the Kantian-style reply that the considerations against creating crime are insuperable.

\section{Conclusion}

We have considered in depth various formulations of the incoherence objection and have reconstructed them in detail and with considerably more rigour than we have come across in the literature so far. We have found an interesting commonality between the versions of the objection proposed by Dworkin and by Ashworth, namely that they both (in their most plausible form) depend on the contention that entrapment serves an end contrary to that of lawenforcement. We have, however, also pointed out that obtaining the conclusion that entrapment is always incoherent would require a strong Kantian-style premise to the effect that the end of preventing crime can never be suspended in the short term for the sake of greater realization in the long term.

The need to add this Kantian-style premise means that the incoherence objection cannot stand on its own, unaided by further arguments and assumptions, as an objection to all entrapment cases. Are there any cases in which the incoherence objection could apply without the Kantian-style duty, because of a particular aim or motive of the agent?'

Without further analysis it is hard adequately to answer this question; still, here are some initial considerations. It is fairly clear that if the agent entraps just to get promoted, say, then that is not a good enough reason to suspend the requirement not to create crime; incoherence, even if we do not assume a Kantian-style duty, would loom large here (given the assumption, upon which both the incoherence objection and our account of legal entrapment rest, that the 
agent is acting in the agent's capacity as a law-enforcement agent). Similar considerations apply if the agent entraps just so as not to get demoted, or just to achieve a certain set number of arrests in a set period. At the other end of the spectrum, we have the examples already mentioned: prevention of more, or more serious, crime in the future, and, also, arresting criminals for crimes in the past. Difficult cases might concern whether the end of preventing civil unrest, or of safeguarding life and limb, would be sufficient to avoid incoherence without assuming a Kantian premise. We do not here pass moral judgement on it; we just note that it would seem somewhat harder to escape the incoherence objection here than it would be by pleading the more idealistic approach of reducing crime in the long term.

List of Cases Referred To

England and Wales

Attorney General's Reference (No. 1 of 1975) [1975] EWCA Crim 1, [1975] QB 773

$\underline{\mathrm{US}}$

Sherman v United States, 356 US 369, 384 (1958) 